\title{
Mummy's boys: sex differential maternal-offspring bonds in semi-feral horses
}

\author{
Christina R. Stanley ${ }^{\mathrm{a}, \mathrm{b}, *}$ and Susanne Shultz ${ }^{\mathrm{b}}$ \\ ${ }^{a}$ Liverpool John Moores University, Liverpool, Merseyside, UK \\ ${ }^{\mathrm{b}}$ Institute of Cultural and Evolutionary Anthropology, \\ University of Oxford, Oxford, UK \\ *Corresponding author's e-mail address: C.R.Stanley@2010.ljmu.ac.uk
}

Accepted 8 March 2012

\begin{abstract}
In polygynous species with high reproductive skew in males, mothers often show differential investment between sons and daughters. Although consistent sex differential investment has not been found by previous studies in horses, maternal investment beyond weaning has often been overlooked. We investigated sex differences in mother-offspring relationships in nutritionally independent sub-adult feral ponies, Equus ferus caballus. Stronger affiliative bonds between mothers and their sons than with their daughters were shown by their maintenance of closer proximity, higher rates of affiliative interactions and more frequent suckling bouts. These were associated with higher aggression levels directed towards sub-adult males by other band members, particularly stallions. We suggest that aggression may serve as the proximate mechanism driving male dispersal in feral horses and that the stronger mother-son bond signals an attempt to delay dispersal, highlighting conflict within the band concerning dispersal timing. Since we used social network theory to show that males become increasingly central within the band over time, we propose that delaying colts' dispersal allows for further development of social skills in a relatively safe environment, maximising their reproductive success. This study illustrates how social network theory can be used to quantify individuals' social experiences, contributing to a greater understanding of the evolution of group living.
\end{abstract}

Keywords

Equus caballus ferus, maternal investment, social network analysis, aggression, group living.

\section{Introduction}

Differential maternal investment between sons and daughters is a common phenomenon and may influence the lifetime reproductive success of offspring. In species with high reproductive skew, male reproductive success 
is often dependent upon adult size and condition (Kruuk et al., 1999). In such cases, mothers in good condition are expected to invest more in sons than in daughters and may potentially alter offspring sex ratio in response to their condition (Trivers \& Willard, 1973; Clutton-Brock et al., 1984). In red deer Cervus elaphus, levels of nutrition in female calves have been shown to have a lesser effect upon growth than in males in their first year of life (Clutton-Brock et al., 1982), so it pays for females in poorer condition to invest more in female than in male offspring (Clutton-Brock et al., 1984). However, whilst this explains sex-skewed differential maternal investment (relating to maternal body condition) in dimorphic species, it may not hold true for monomorpic species such as horses (Equus caballus), where adult body size does not determine either dominance or reproductive success (Berger, 1977, though see Houpt et al., 1978), yet reproductive skew still exists. Maternal investment may, therefore, manifest itself in behaviours such as increased tolerance or social support of nutritionally independent young, which are not directly related to increasing calorific input.

Feral horses commonly live in stable bands consisting of a single stallion (adult male), a core group of closely bonded mares (adult females) and their pre-dispersal offspring (Mills \& McDonnell, 2005). Previous efforts to identify sex-biased maternal investment in horses have been unsuccessful; however, although juveniles remain in their natal herd until dispersal at aged two to three years (Berger, 1986), most maternal investment studies have concentrated on maternal investment in nutritionally dependent foals of under a year old. No sex bias has been found in terms of weaning dates (Cameron \& Linklater, 2000), the maintenance of proximity between mother and foal (Cameron \& Linklater, 2000; Weeks, 2000), the recumbency response (Weeks, 2000) or spatial relationships (Cameron \& Linklater, 2000; Cameron et al., 2000; Weeks, 2000). More detailed provisioning measures including suckling bout duration and frequency have been suggested as better measures of maternal investment in horses (Crowell-Davies, 1985; Barber \& Crowell-Davies, 1994); however, although mares allow young colt foals to suckle longer than female foals, this difference disappears after the 8-week stage and does not translate into a weight dimorphism at 26 weeks (Duncan et al., 1984). Additionally, Cameron et al. (1999a) showed that suckling measures do not relate to the energy intake the foal receives. Two alternative suckling measures, the percentage of suckling bouts ended by the mother and the percentage of unsuccessful suckling bouts (Cameron et al., 1999b), 
also showed no significant differences between foal sexes. In fact, only a single study has demonstrated sex-biased investment: Cameron \& Linklater (2000) found that mares in good condition invested more in sons and those in poor condition invested more in daughters. We, therefore, chose to look at mother-offspring relationships in older offspring to investigate the possibility of sex-biased investment at this developmental stage.

Extended juvenile periods are necessary for highly social species to learn appropriate social behaviours (Dunbar, 1988; Joffe, 1997). In other mammals, the juvenile period has been shown to be important for learning about rank, dominance and forming affiliative relationships (Joffe, 1997). Delaying dispersal until aged two to three years old (Berger, 1986) provides an opportunity for further social learning and physical development in horses and reduces the time period between dispersal and harem formation for young colts (Khalil \& Murakami, 1999). By delaying dispersal and learning about social relationships in the natal group, as opposed to moving straight into a bachelor herd, juveniles can rely on their mothers for protection and aid during conflict. Social network centrality measures of sub-adults may give an insight into each sex's social experiences across the juvenile period (e.g., Hansen et al., 2009). If social learning is an important benefit of remaining in the natal herd, we would expect centrality to increase with age as juveniles extend their active social network. Although female reproductive success is associated with maintaining social relationships (Cameron et al., 2009), due to the high reproductive skew in equid males, we would expect males to benefit significantly more from social learning; we would, therefore, expect sub-adult males to be more highly central in the network than their female peers.

Delayed dispersal, however, can cause conflict within an equid band. Harassment by young males can reduce condition and reproductive success in females in multi-stallion bands (Linklater et al., 1999). Colts are potential competitors with resident stallions; subordinate stallions sired around 25\% of foals in a band of Camargue horses (Feh, 1999). Unsurprisingly, both stallions and mares use aggression to evict juvenile males from harems (Hall \& Kirkpatrick, 1975). Fillies, on the other hand, do not seem to suffer from as much aggression from other herd members (Monard et al., 1996); perhaps they maintain a more peripheral position and are, therefore, less likely to be a potential target. Sex differential investment in horses may, therefore, manifest itself in maternal responses to this aggression directed at her male 
offspring, as has been found in primates (Maestripieri, 1998). Mothers and male offspring may maintain closer proximity (Fairbanks, 1996), may increase the frequency of affiliative interactions and mothers may allow older juveniles to suckle when threats are more frequent.

Here we evaluate sex differences in sub-adult social behaviour and maternal relationships in semi-feral ponies. As male reproductive success in a sexually skewed species is dependent upon successfully acquiring and holding a harem, we predict sub-adult males to be involved in more social interactions with other herd members than fillies and for this discrepancy to be reflected by centrality measures. Since they are likely to be a nuisance to other band members, we predict colts to suffer from higher aggression rates than fillies. We predict that dams will counteract this aggression by allowing closer proximity and engaging in higher levels of affiliation, which are necessary to enable colts to remain in the band and benefit from social learning. Conversely, we would expect fillies to receive lower levels of aggression, be more peripheral in the herd prior to dispersal and receive less maternal investment.

\section{Materials and methods}

\subsection{Study animals and field site}

This study was conducted in the Carneddau mountain range, part of the Snowdonia National Park, North Wales $\left(53.22^{\circ} \mathrm{N}, 3.95^{\circ} \mathrm{W}\right)$ from February 2009 to November 2010, with observations spread out to cover all seasons. The study site consisted of mountainous terrain ranging in altitude from $250-950 \mathrm{~m}$. The primary land uses in the region are sheep pasture and recreational hiking. The region experiences an oceanic climate with average annual temperatures from $6-10^{\circ} \mathrm{C}$ (Snowdonia National Park Authority, 2007) and annual rainfall exceeding $3000 \mathrm{~mm}$ (Met Office, 2007). The study population consisted of around 200-300 semi-feral Carneddau-type Welsh mountain ponies (Equus caballus) which ranged freely across an area of almost 200 square kilometres; 51 of these individuals were regularly observed as part of this study. The population is relatively unmanaged, with no interference apart from a round-up in November, when excess colts are sometimes removed from the population, depending on the current management strategy. However, no colts were removed from the population in the 
few years preceding the start of this study, so sub-adult males and potential bachelors were present.

Individuals are well habituated to humans; in addition to the presence of the two researchers they come into frequent contact with hill walkers. Both researchers maintained a sufficient observation distance (approx. 10-20 m), so as not to cause ponies to change behaviour (to our knowledge). Individuals were photographed and readily identified by distinctive markings, coat colour and ear notches. Ages of sub-adults (12-36 months) were known for most youngsters from photographic records of foals born since 2007; where year of birth was not known, it was estimated by comparison of body size and shape with youngsters of known age. Maternal identities were determined by observations of suckling events between all mare-offspring dyads. Two of the three focal bands have been studied since 2007. Two bands had a single adult male whereas one had two; since one of these two was a four year old not observed to engage in sexual behaviour, this was classed as a sub-adult male but was excluded from analyses as his maternal identity was unknown. The three bands' home ranges overlapped considerably, but the bands were usually at least a kilometre apart. Fifty-one individuals were studied; total band sizes were 27, 15 and 11 in 2009 and 24, 20 and 16 in 2010 (see Table 1 for band composition). In the November 2009 round-up, seven colt sub-adults and three colt foals were removed from focal bands 'Aber' and 'Marsh', whilst 'Anafon' remained unchanged. An individual's band membership was determined by both range use and association patterns; the band as a whole constitutes all individuals which associate with each other frequently over time, with fission and fusion events altering the composition of subgroups within this band.

\subsection{Observation methods}

Data were collected on a weekly basis between 10 am and 4 pm, with sampling effort remaining relatively constant across the day and throughout the year (apart from winter, when access was restricted due to snow) in order to cover seasonal variation in aggression levels. A total of $224 \mathrm{~h}$ of observations were carried out over 58 days by C.S and S.S.; methodology was strictly adhered to in order to ensure inter-observer reliability.

Horses show high levels of fission-fusion dynamics (Aureli et al., 2008), with the main band separating into smaller sub-groups and then recombining continually over time. When a sub-group was encountered, the individuals 
Table 1.

Focal band composition.

\begin{tabular}{|c|c|c|c|c|c|c|}
\hline Class & Year & $\begin{array}{l}\text { Age } \\
\text { class }\end{array}$ & 'Aber' & 'Anafon' & 'Marsh' & Total \\
\hline \multirow[t]{2}{*}{ Stallions } & 2009 & & 1 & 1 & 1 & 3 \\
\hline & 2010 & & 1 & 1 & 1 & 3 \\
\hline \multirow[t]{2}{*}{ Bachelors } & 2009 & & 0 & 1 & 0 & 1 \\
\hline & 2010 & & 0 & 1 & 0 & 1 \\
\hline \multirow[t]{2}{*}{ Mares } & 2009 & & 10 & 7 & 6 & 23 \\
\hline & 2010 & & 10 & 8 & 8 & 26 \\
\hline \multirow[t]{2}{*}{ Fillies } & 2009 & & 8 & 2 & 2 & 12 \\
\hline & 2010 & & 9 & 7 & 6 & 22 \\
\hline \multirow[t]{2}{*}{ Colts } & 2009 & & 8 & 4 & 2 & 14 \\
\hline & 2010 & & 4 & 3 & 1 & 8 \\
\hline \multirow[t]{2}{*}{ Total } & 2009 & & 27 & 15 & 11 & 53 \\
\hline & 2010 & & 24 & 20 & 16 & 60 \\
\hline \multirow[t]{3}{*}{ Fillies } & 2009 & Foals & 5 & 1 & 1 & 7 \\
\hline & & Yearlings & 2 & 1 & 0 & 3 \\
\hline & & Two years & 1 & 0 & 1 & 2 \\
\hline \multirow[t]{3}{*}{ Colts } & & Foals & 3 & 0 & 0 & 3 \\
\hline & & Yearlings & 1 & 3 & 2 & 6 \\
\hline & & Two years & 4 & 1 & 0 & 5 \\
\hline \multirow[t]{3}{*}{ Fillies } & 2010 & Foals & 2 & 4 & 4 & 10 \\
\hline & & Yearlings & 5 & 1 & 2 & 8 \\
\hline & & Two years & 2 & 2 & 0 & 4 \\
\hline \multirow[t]{3}{*}{ Colts } & & Foals & 4 & 0 & 1 & 5 \\
\hline & & Yearlings & 0 & 3 & 0 & 3 \\
\hline & & Two years & 0 & 0 & 0 & 0 \\
\hline
\end{tabular}

'Aber', 'Anafon' and 'Marsh' are the three focal bands. For top half of table, Stallions are breeding adult males, Bachelors are non-breeding adult males, Mares are adult females, Fillies are juvenile females under 3 years old and Colts are juvenile males under 3 years old. Juveniles are then split into age classes in bottom half of table: Foals are under one year old, Yearlings are $1-2$ years, Two years are $2-3$ years old.

present, their behaviour and spatial distribution were recorded, with the distance between each pair of neighbouring individuals being estimated and recorded on a diagram. Individuals were assigned to a sub-group when they were within $200 \mathrm{~m}$ of at least one other sub-group member and maintained this level of proximity or less over the sampling period. If they moved outside of this range, they were assigned to a separate sub-group; above this distance, individuals could be out of sight and missed by observers. Also individuals did not appear to maintain proximity with other subgroups above this dis- 
tance. Initially, both researchers worked separately and compared distance estimates until consistency in estimations was achieved. Distance estimates were then compared regularly to ensure reliability. Where individuals were less than $15 \mathrm{~m}$ apart, they were considered as a single cluster and all dyadic distances were recorded as $15 \mathrm{~m}$; below this, inter-individual distances were highly variable and difficult to estimate. This was repeated at half-hourly intervals.

Focal-animal sampling (Altmann, 1974) was also carried out for ten minute periods on randomly chosen individuals, recording the identities of their two nearest neighbour conspecifics at one minute intervals and their distances from the focal individual (in $\mathrm{m}$, estimated by eye to the nearest $5 \mathrm{~m}$ up to a distance of $50 \mathrm{~m}$ and to the nearest $10 \mathrm{~m}$ above this). One-minute sampling was used so that an average could be taken across the 10-min period to ensure the final dyadic distances recorded were representative of the true distances maintained between individuals. Foal distances from dams was also recorded where the focal individual had a foal at foot. A total of $37 \mathrm{~h}$ of focal sampling (370 samples) were carried out; since all foals were born during the same three week period and sampled consistently during the following months, maternal behaviour across different foal ages was recorded for all individuals, reducing foal age effects on results.

All social behaviour was recorded on an all-occurrence basis (Altmann, 1974); these were recorded as events by pen and paper. Social behaviour recorded included aggressive interactions, affiliative interactions, suckling and sexual behaviour. Aggressive interactions were categorised as those listed and defined by Vervaecke et al. (2006): Ears laid back, Bite threat, Bite, Kick threat, Kick, Attack, Chase, Fight, Shouldering, Push back, Strike and Threat approach. All other interactions (where one individual approached another and touching or sniffing occurred) were described as affiliative. Exceptions to this were suckling behaviour and sexual interactions (where a male approached a female and either attempted to mount her or exhibited flehmen behaviour). The individuals involved and directionality of the interaction (i.e., instigator, aggressor etc.) were also recorded. However, directionality of affiliative behaviour between dam and offspring was not always recorded. From these data we collated the frequencies of aggressive and affiliative events received per day for each sub-adult and foal. For each individual, these were then converted into rates of events per minute by dividing by the time period the individual had been observed for. Mean values for total 
rate of aggression, rate of stallion aggression, mare aggression and dam affiliation recorded towards each sex and age class were then calculated. Where suckling attempts by foals were observed, the number of times a dam refused to allow her foal to suckle before a successful suckling bout was initiated (a common maternal control behaviour in horses, Duncan et al., 1984) was also recorded as a measure of maternal investment; these data were then converted into the percentage of suckling attempts refused (of all suckling attempts by foals).

Stallions were not always present in focal sub-groups; therefore, aggression rates received from stallions were calculated for only observation periods with a stallion present. Aggression rates received from mares were calculated for all observation periods with a non-dam mare present.

\subsection{Statistical analysis}

Juveniles were categorised according to sex and age ( $0, x \leqslant 1$ year; 1 , $1<x<2$ years; 2, $2<x<3$ years). Aggression and affiliation were recorded as frequencies within observation periods, such that there were repeated measures for each sub-group for each observation period; they were then converted to rates per sub-group observation period. As both aggression and affiliation within a given sub-group were relatively infrequent, the data had a central tendency of zero and were over-dispersed. For all analyses of aggression and affiliation received (dependent variables), we therefore used Generalised Estimating Equations (GEE) with a Poisson distribution and loglink error structure. We chose to use GEEs for two reasons: (1) it allows the use of a non-Gaussian distribution in the response variable (aggression and affiliation had a mass at zero and a strong right skew) and (2) GEE's allow for repeated measures of individuals. As we have repeated sampling of focal individuals across multiple years, we required a model structure allowing both an appropriate probability distribution and a repeated measures design. Together with individual ID (repeated measure), GEE models included age, sex, an age $\times$ sex interaction and season as factors. For all GEE models, we report Wald's chi-square for each model factor and QICC (corrected quasi-likelihood information criterion), where smaller values indicate a better model fit (Pan, 2001). Relative model fit was evaluated by the change in QICC from the best fit model and by model weight (Table 2). The relative weight of evidence for each candidate model was calculated using the following equation: $w_{i}=\exp (-0.5 \Delta i) / \sum \exp (-0.5 \Delta i)$, where $\Delta i$ represents 
Table 2.

Alternative model results for total aggression (stallion plus non-dam mares).

\begin{tabular}{|c|c|c|c|c|c|c|c|}
\hline Variable & Model & Factor & $(\mathrm{QICC})^{\mathrm{a}}$ & $\Delta \mathrm{QICC}$ & Model weight & Wald $\chi^{2}$ & $p$ \\
\hline \multirow{12}{*}{$\begin{array}{l}\text { Total } \\
\qquad \text { aggression } \\
\quad(41,687)\end{array}$} & \multirow[t]{4}{*}{1} & Sex & \multirow{4}{*}{513.109} & & & 6.166 & 0.013 \\
\hline & & Age & & & $>0.999$ & 67.861 & $<0.001$ \\
\hline & & Sex $\times$ Age & & & & 59.966 & $<0.001$ \\
\hline & & Season & & & & 5.212 & 0.074 \\
\hline & \multirow[t]{3}{*}{2} & Sex & & & & 12.833 & $<0.001$ \\
\hline & & Age & 531.032 & 17.923 & $<0.001$ & 15.693 & 0.001 \\
\hline & & Season & & & & 4.677 & 0.096 \\
\hline & \multirow[t]{2}{*}{3} & Sex & 537.28 & 24.171 & $<0.001$ & 14.179 & $<0.001$ \\
\hline & & Season & & & & 3.924 & 0.141 \\
\hline & \multirow[t]{2}{*}{4} & Age & 553.709 & 40.6 & $<0.001$ & 46.051 & $<0.001$ \\
\hline & & Season & & & & 4.568 & 0.102 \\
\hline & 5 & Season & 566.189 & 53.08 & $<0.001$ & 3.207 & 0.201 \\
\hline \multirow{12}{*}{$\begin{array}{l}\text { Stallion } \\
\qquad \text { aggression } \\
\quad(41,687)\end{array}$} & \multirow[t]{4}{*}{1} & Sex & & & & 5.275 & 0.022 \\
\hline & & Age & 296.596 & & 0.971 & 49.016 & $<0.001$ \\
\hline & & Sex $\times$ Age & & & & 7.025 & 0.03 \\
\hline & & Season & & & & 1.213 & 0.545 \\
\hline & \multirow[t]{3}{*}{2} & Sex & & & & 13.116 & $<0.001$ \\
\hline & & Age & 303.685 & 7.089 & 0.028 & 24.549 & $<0.001$ \\
\hline & & Season & & & & 1.035 & 0.596 \\
\hline & \multirow[t]{2}{*}{3} & Sex & 311.889 & 15.293 & $<0.001$ & 14.382 & $<0.001$ \\
\hline & & Season & & & & 0.617 & 0.735 \\
\hline & \multirow[t]{2}{*}{4} & Age & 320.862 & 24.266 & $<0.001$ & 21.319 & $<0.001$ \\
\hline & & Season & & & & 0.968 & 0.616 \\
\hline & 5 & Season & 336.081 & 39.485 & $<0.001$ & 0.244 & 0.885 \\
\hline \multirow{12}{*}{$\begin{array}{l}\text { Mare } \\
\text { aggression } \\
(41,687)\end{array}$} & \multirow[t]{2}{*}{1} & Sex & 300.761 & & 0.466 & 4.251 & 0.039 \\
\hline & & Season & & & & 7.863 & 0.02 \\
\hline & \multirow[t]{4}{*}{2} & Sex & & & & 5.877 & 0.015 \\
\hline & & Age & 301.13 & 0.369 & 0.387 & 3.442 & 0.328 \\
\hline & & Sex $\times$ Age & & & & 6.138 & 0.046 \\
\hline & & Season & & & & 8.403 & 0.015 \\
\hline & 3 & Season & 304.256 & 3.495 & 0.081 & 7.563 & 0.023 \\
\hline & \multirow[t]{3}{*}{4} & Sex & & & & 3.674 & 0.055 \\
\hline & & Age & 305.18 & 4.419 & 0.051 & 1.645 & 0.649 \\
\hline & & Season & & & & 8.077 & 0.018 \\
\hline & \multirow[t]{2}{*}{5} & Age & 307.606 & 6.845 & 0.015 & 3.361 & 0.339 \\
\hline & & Season & & & & 8.335 & 0.015 \\
\hline
\end{tabular}

the change in QICC between the best model (lowest QICC) and alternative models (Johnson \& Omland, 2004). 
Table 2.

(Continued.)

\begin{tabular}{|c|c|c|c|c|c|c|c|}
\hline Variable & Model & Factor & $(\mathrm{QICC})^{\mathrm{a}}$ & $\Delta \mathrm{QICC}$ & Model weight & Wald $\chi^{2}$ & $p$ \\
\hline \multirow{12}{*}{$\begin{array}{l}\text { Dam } \\
\text { affiliation } \\
\quad(29,687)\end{array}$} & 1 & Sex & 215.021 & & 0.692 & 8.945 & 0.003 \\
\hline & & Season & & & & 17.558 & $<0.001$ \\
\hline & 2 & Sex & & & & 5.857 & 0.016 \\
\hline & & Age & 217.448 & 2.427 & 0.206 & 7.641 & 0.054 \\
\hline & & Sex $\times$ Age & & & & 0.12 & 0.729 \\
\hline & & Season & & & & 18.818 & $<0.001$ \\
\hline & 3 & Sex & & & & 6.435 & 0.011 \\
\hline & & Age & 218.88 & 3.859 & 0.100 & 2.253 & 0.522 \\
\hline & & Season & & & & 18.329 & $<0.001$ \\
\hline & 4 & Season & 228.086 & 13.065 & 0.001 & 18.133 & $<0.001$ \\
\hline & 5 & Age & 228.215 & 13.194 & 0.001 & 4.844 & 0.184 \\
\hline & & Season & & & & 21.906 & $<0.001$ \\
\hline
\end{tabular}

Degrees of freedom are shown in parentheses (subjects, samples). Corrected Quasi Likelihood under Independence Model Criterion ( QICC $^{\mathrm{a}}$ ) is reported to assess relative model fit (lowest value is best fit). Best model chosen as one with lowest QICC $^{\mathrm{a}}$ score; model weight shows strength of best model when compared with alternative models.

Season was classed as either non-breeding (September to February), foaling/mating (March to May) or raising young (June to August). We initially tried using four 3-month blocks as seasons, but data from September to November and December to February were then combined as aggression levels were similarly low and variable across these two time periods.

For proximity analyses, where dyadic distances were normally distributed, we used a nested ANOVA with sex and ID within sex as main factors. Data for sub-adults were analysed in a separate ANOVA to data for foals. Total frequencies of sub-adults seen nursing were analysed using chi-squared tests and the percentage of suckling attempts by foals refused by dams were compared using a Mann-Whitney $U$-test since data could not be normalised. Half-weight indices were calculated (Cairns \& Schwager, 1987) for all dyads in order to determine the time each dyad spent in association, i.e., within the same sub-group. These were compared using Mann-Whitney $U$-tests.

\subsection{Social network analysis}

We employed social network metrics to evaluate the position of individuals within bands; for example, being highly central to the network can mean an individual is able to act as an important broker for the transmission of information (Croft et al., 2008). Centrality can be calculated for individuals using 
a number of measures; we used both closeness centrality and betweenness centrality since different centrality measures can give very different answers in terms of an individual's social position (Landherr et al., 2010). Closeness centrality considers the geodesic distances to all the other actors in the network and so takes into account indirect as well as direct ties (Wasserman \& Faust, 1994), whilst betweenness centrality calculates the proportion of shortest pathways between all individuals in group which go through a certain individual (Sih et al., 2009).

Band composition is fairly coherent; thus, one-zero association sampling provides poor resolution of social position within sub-groups. In order to evaluate individual differences in social position, we therefore used inter-individual distances to enable weighted vertices to be calculated. Interindividual distances are rarely used in animal social network analysis; this may be due to most social animal groupings occurring in dense habitats or under water. For horses, it is usually possible to see the entire subgroup at once and so these more detailed data can be reliably collected, giving an accurate snapshot of spatial associations which can be averaged over time. Data on spatial relationships between individuals from scans were first tabulated and weighted; since the minimum distance between individuals was recorded as $15 \mathrm{~m}$ (for individuals tightly clustered together), weighting was calculated as 15 divided by the distance value. Individuals not recorded during a scan (i.e., outside a $200-\mathrm{m}$ radius) received a weighting of zero with all recorded individuals. A mean dyadic weight (i.e., the average of all weights recorded between the two individuals) was then calculated for each possible pairing of individuals; this included dyads comprising members of different bands which were never seen to be associated and, therefore, gained a weighting of zero. These means were then used to produce a weighted sociomatrix.

The weighted sociomatrix was analysed using the computer software 'R' (http://cran.r-project.org) with packages tnet (Opsahl, 2011) and igraph (Csardi, 2011). Weighted values for closeness and betweenness centrality were calculated for each individual and analysed in SPSS. Generalised linear models were employed using distributions appropriate for these data; closeness was analysed using a gamma distribution with log link error structure due to its right skew, whilst betweenness was analysed using a Poisson distribution with a log link error structure due to its significant mass at zero and right skew. Sex and band were treated as factors, with age class being included as a covariate; models included sex, band, age class and a sex $\times$ age class interaction term. 


\section{Results}

To date, we have identified 134 individuals, of which 94 were females; we therefore estimate the population sex ratio to be approx. 11: 5 females to males. Bachelor herds have been recorded but most individuals live in breeding bands. We recorded a total of 80 instances of stallion aggression and 75 of mare aggression across the 43 sub-adult and foals observed during the two year study. Within sub-group observation periods, aggressive behaviour was always observed at least once. Mean aggression rate received from the stallion $\pm \mathrm{SD}$ was $0.09 \pm 0.02$ events per hour; mean aggression rate received from mares \pm SD was $0.05 \pm 0.01$ events per hour. The Carneddau ponies have a social structure with a high level of fission-fusion dynamics; sub-group sizes ranged from 2 to 22 individuals (median $=5$ ). Between 2009 and 2011, 39 foals were born to focal individuals; 14 were male and 25 female. Of the six mares in 2009 with both a pre-dispersal sub-adult and foal at foot, four had colt sub-adults and two fillies; of the nine mares in 2009 with just a pre-dispersal sub-adult present, six had colts and three fillies. For focal samples, effort was divided approximately equally between dam-offspring dyads containing sub-adult males and with those containing sub-adult females; a total of 93 focal samples were carried out on members of mother-colt dyads $(N=10$, mean $=9.3$ per dyad $)$ and 50 focal samples were carried out on members of mother-filly dyads $(N=5$, mean $=10$ per dyad).

\subsection{Total aggression}

Total aggression levels were highest between March and August and lowest between September and February (Figure 1a). For this reason, seasonality was included as a factor in the GEE models. Total aggression received by sub-adults was a function of both age and sex. The best fit model (with the lowest QICC ${ }^{\mathrm{a}}$, see Table 2; other models tested are shown for comparison of relative weighting and model fit) included age, sex and season, with sex and age (and also their interaction) being the most important factors. One- and 2-year-old colts received significantly more aggression than either colt foals or fillies of any age (Figure 2a). Stallions were significantly more aggressive towards colts than fillies, and least aggressive towards foals, with season not impacting significantly (Table 2, Figure $2 b$ ). Stallions were seen to sexually harass two sub-adult fillies during the study (i.e., stallions attempted to 


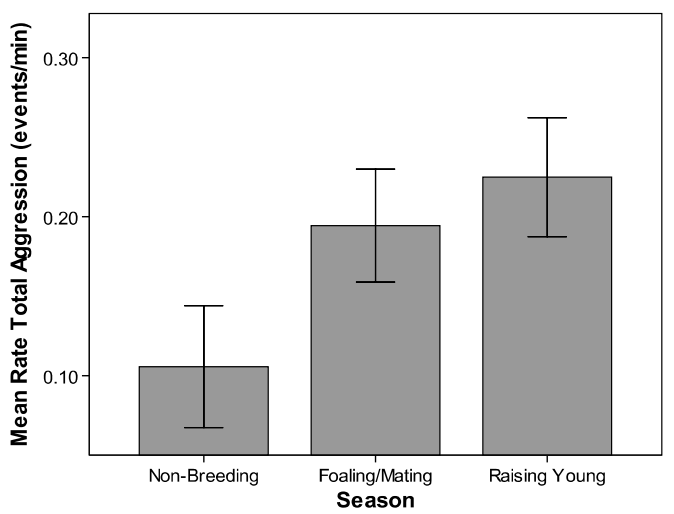

(a)

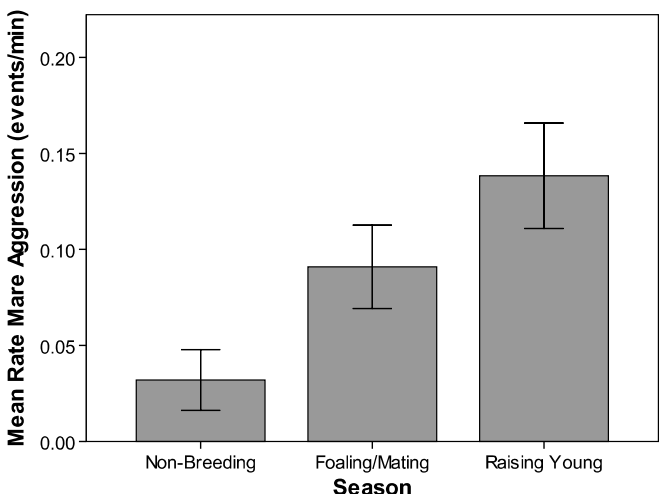

(b)

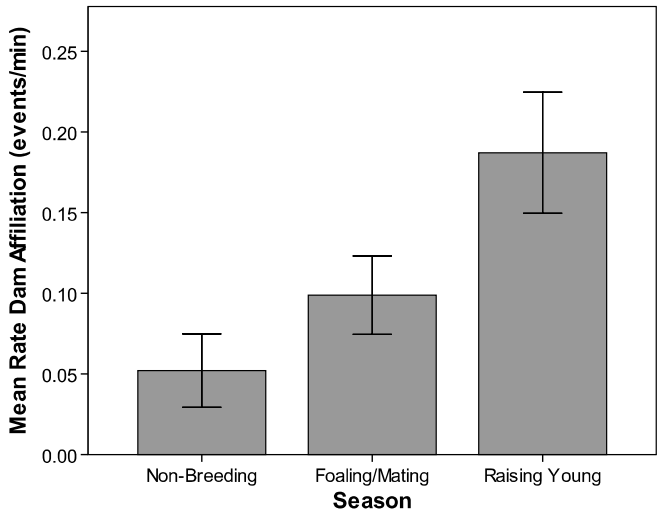

(c)

Figure 1. The effect of season on total (a) and mare (b) aggression rates and on dam affiliation rates (c). Season was classed as follows: $1=$ non-breeding (September to February), $2=$ foaling/mating (March to May), 3 = raising young (June to August). Error bars represent standard errors. 


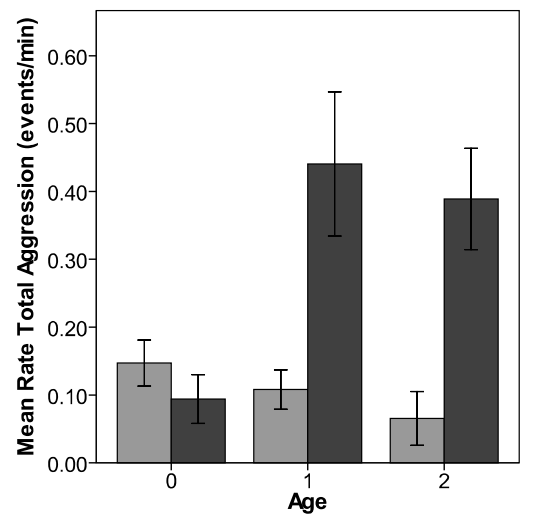

Sex

$\square$ female

(a)

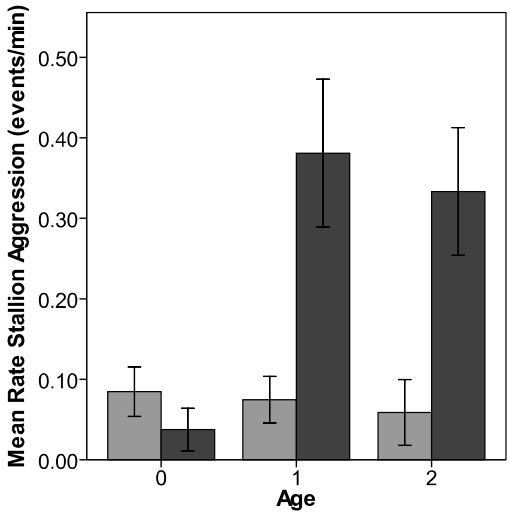

Sex

$\square$ female

$\square$ male

(b)

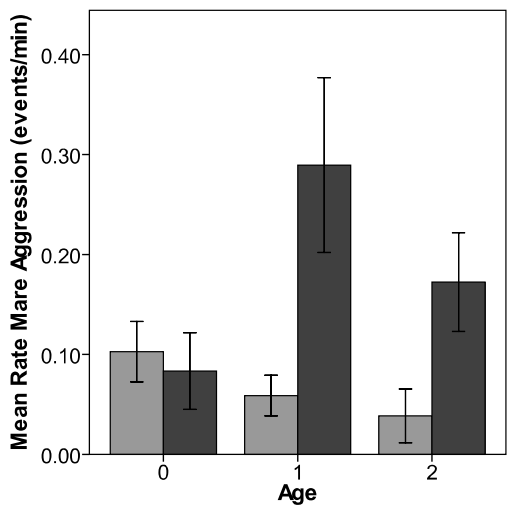

Sex

$\square$ female

$\square$ male

(c)

Figure 2. Total (a), stallion (b) and mare (c) aggression rates towards sub-adults and foals. See text for age classification. Error bars represent standard errors. 
mount fillies or followed fillies closely and repeatedly with constant sniffing/flehmen). Non-dam mares were significantly more aggressive towards colts than fillies of all ages (Table 2, Figure 2c), with aggression levels being significantly higher between March and August (Figure 1b). There were also nine incidences of one to two year old colts sexually harassing both adult and sub-adult mares; each time, aggression was received by the colts from the mare.

\subsection{Dam-offspring affiliative interactions and proximity to offspring}

Using a Generalised Estimating Equation, the best fit model showed sex and season as the key factors (Table 2), with dams and their colts being significantly more affiliative towards each other than were dams and their fillies (Figure 3). Dams were not more affiliative towards any age group. Damoffspring affiliative interactions were significantly higher between June and August than in other seasons (Figure 1c).

There was no sex difference in the half-weight index of association between dams and their sub-adult offspring (Mann-Whitney $U$-test: $U=25$, $N=15, p>0.999$ ). Dams and their sub-adult colt offspring maintained closer proximity to each other (mean distance \pm SD $17.9 \pm 2.1 \mathrm{~m}$ ) than dams and sub-adult fillies (mean $\pm \mathrm{SD} 28.8 \pm 2.3 \mathrm{~m} ; F_{1,97}=11.79, p=0.001$ ). In addition to a sex effect, individual dams differed in their average proximity to their sub-adult offspring (ID $F_{14,97}=2.06, p=0.021$ ). However, when a separate ANOVA was conducted for foal data, there was no difference in proximity to dams' first year foals, either as a function of sex (filly mean \pm

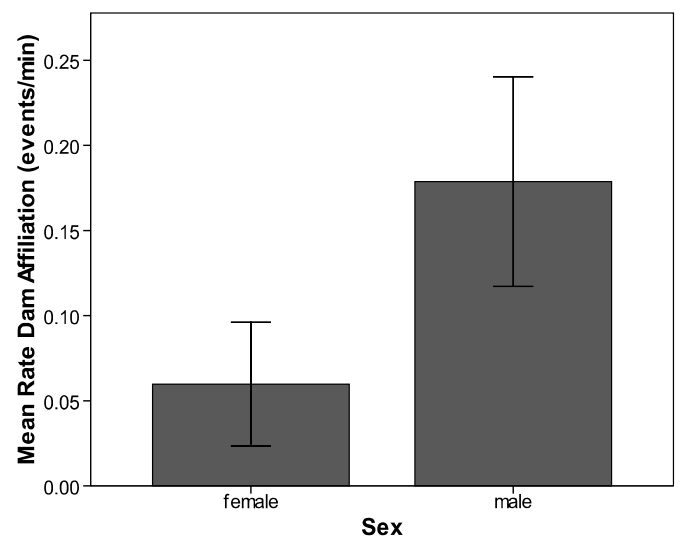

Figure 3. Rates of dam affiliation received by sub-adults. Error bars represent standard errors. 
SD $17.33 \pm 3.11$, colt mean \pm SD $\left.16.96 \pm 5.13 ; F_{1,22}=0.004, p=0.95\right)$ or dam ID $\left(F_{7,22}=0.663, p=0.70\right)$.

There was no difference between the percentage of suckling attempts refused between male and female foals (Mann-Whitney $U$-test: $U=20.5$, $N=15, p=0.568)$. Dams were seen to nurse their 1-2-year-old colts significantly more than their fillies $\left(\chi^{2}=2.618, \mathrm{df}=1, p<0.05\right)$ in 2009 (i.e., before any colt removals occurred).

Dam-offspring affiliation was positively associated with stallion $(\beta=$ 0.440; Wald $\left.\chi^{2}=14.27, p<0.001\right)$, mare $\left(\beta=0.440\right.$; Wald $\chi^{2}=14.27$, $p<0.001)$ and total $\left(\beta=0.844\right.$; Wald $\left.\chi^{2}=51.23, p<0.001\right)$ aggression levels. As these samples were temporally related, i.e., affiliation and aggression events occurring during the same sample period were matched and, therefore, analysed together, this suggests that dam-offspring affiliation is directly associated with aggression from non-kin group members. Directionality of affiliative interactions between dams and their offspring was only recorded infrequently and so could not be analysed statistically.

\subsection{Centrality}

A sociomatrix was produced for each band and the resultant individual centrality metrics were combined. Band identity was retained as a factor in Generalised Linear Models and was a significant factor for both centrality measures (Table 3 ). The sex $\times$ age class term was significant for both closeness centrality and betweenness centrality (Table 3). As shown on Figures $4 \mathrm{a}$ and $\mathrm{b}$, centrality significantly increases with age class for males whilst for females this remains roughly constant (although betweenness appears to be higher for sub-adult females, Figure 4b). Sex and age class both have separate significant effects upon betweenness centrality but not on closeness centrality (Table 3).

\section{Discussion}

Carneddau pony dams have more affiliative interactions, suckling events and allow closer proximity with juvenile sons than juvenile daughters. As in previous studies (Cameron et al., 2000; Weeks, 2000), there was no sex difference between mother and foal proximity, nor was there a difference in the number of foal suckling attempts refused by the mother. Directionality of interactions was not measured by this study so we are unable to distinguish 
Table 3.

Results for Generalised Linear Models using two centrality metrics, closeness and betweenness.

\begin{tabular}{lcrrr}
\hline Variable & Source & Wald $\chi^{2}$ & df & \multicolumn{1}{c}{$p$} \\
\hline Closeness & Band & 431.972 & 2 & $<0.001$ \\
& Sex & 3.666 & 1 & 0.056 \\
& Age class & 0.385 & 1 & 0.535 \\
Betweenness & Sex $\times$ Age class & 5.231 & 1 & $<0.050$ \\
& Band & 207.035 & 2 & $<0.001$ \\
& Sex & 7.532 & 1 & $<0.010$ \\
& Age class & 75.832 & 1 & $<0.001$ \\
& Sex $\times$ Age class & 37.178 & 1 & $<0.001$ \\
\hline
\end{tabular}

between whether this is a mother-driven or son-driven behaviour; this could be determined by future research. However, we can conclude that the affiliative bond between mother and son is stronger than that between mother and daughter at this age. Season has a strong impact on mare behaviour, significantly affecting both non-dam aggression rates and dam affiliative rates towards youngsters, whilst stallion aggression rates are not significantly affected by season.

Mother-son affiliation was temporally related to higher rates of aggression received by colts; this suggests stronger maternal relationships with male offspring may counteract other band members' efforts to evict colts. Maturing colts are potential competitors with the resident stallion and it is in his interest to expel young males from the band (Rutberg \& Keiper, 1993); we showed sub-adult males received the highest rates of aggression from stallions. Mares can be aggressive towards youngsters of both sexes, particularly to the offspring of lower-ranking mares (Rutberg \& Greenberg, 1990); discouraging both sexes from staying in the natal herd can reduce resource competition. However, mare aggression towards colts can additionally be a response to sexual harassment, which impacts upon mares' well-being and reproductive success (Linklater et al., 1999). Thus, mares may apply more pressure to evict colts than fillies from the natal band, as shown by higher levels of aggression shown towards colts in the breeding season; a strong relationship with their mother could provide colts with protection and social support. 


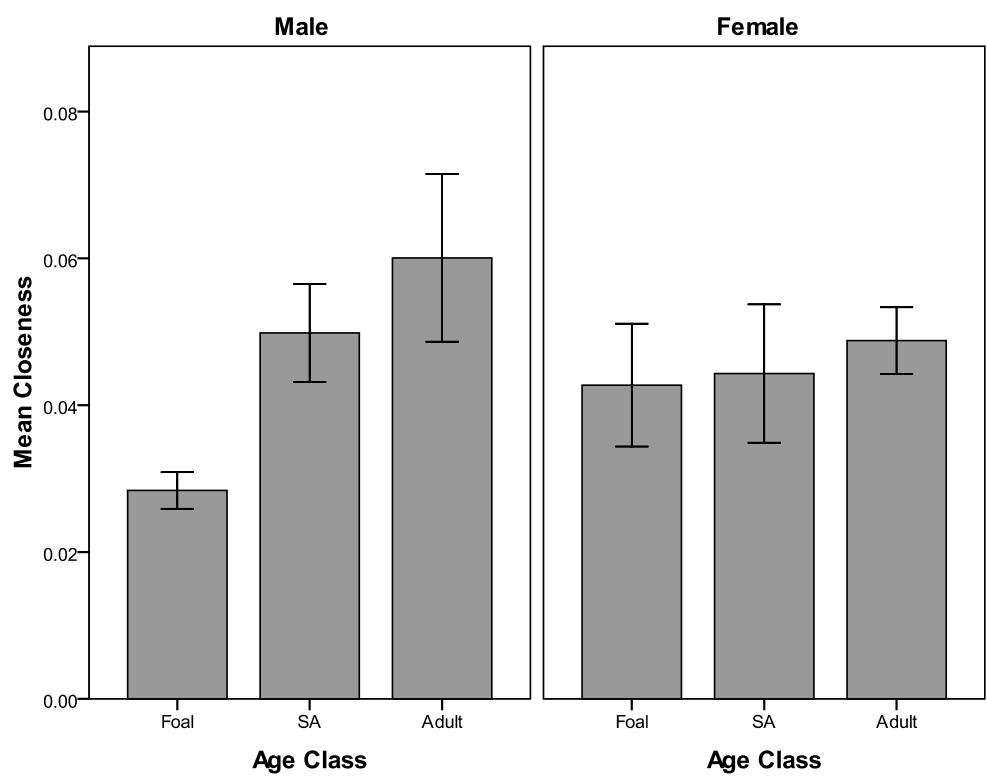

(a)
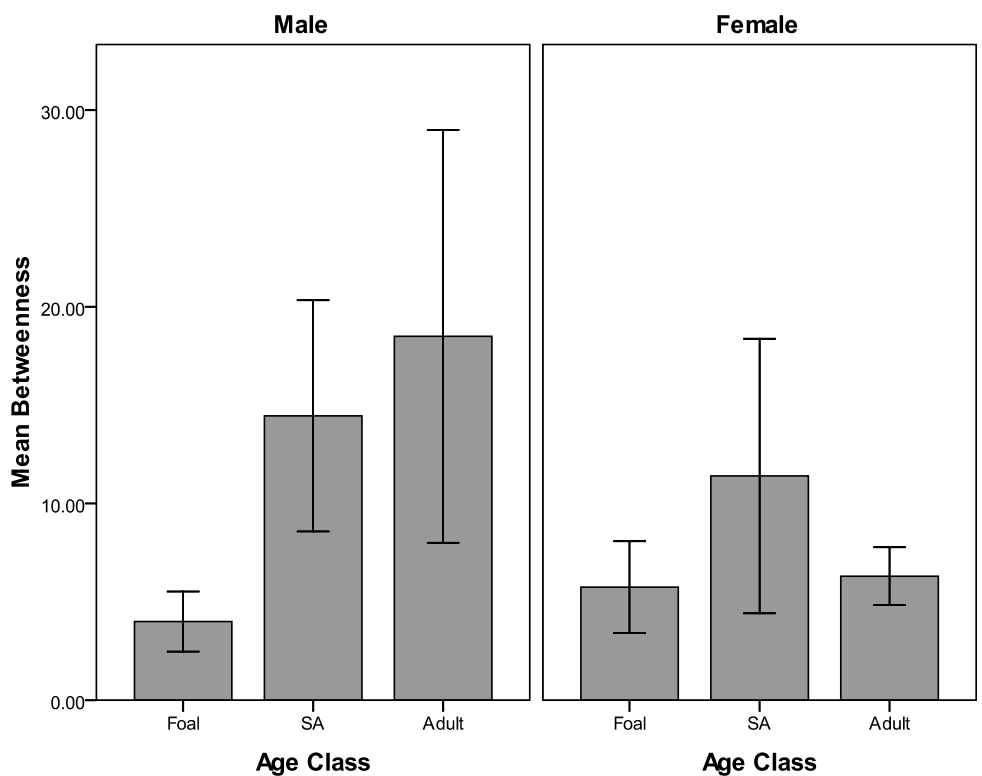

(b)

Figure 4. Mean centrality measures split by age class (Foal $=$ under 1 year, $\mathrm{SA}=$ sub-adult 1-3 years, Adult $=3$ years plus) within each sex. Measures used are (a) closeness and (b) betweenness centrality. Error bars represent standard errors. 
It is important to contextualise the different measures of potential maternal-offspring investment. The frequency of co-occurrence in a subgroup was used to calculate half-weight association indices; however, the resulting association indices did not differentiate between mother-offspring dyads as they all frequently remain in the same sub-group, independent of offspring sex. Although proximity between mother and offspring is easy to record and provides fine scale indication of spatial relationships, it does not, in itself, indicate costly investment by the mother. Preferential suckling of juveniles is a more useful measure; although it could indicate differential nutritional investment in the offspring, suckling of sub-adults occurs at such low frequencies that we treat it as non-nutritive. Its occurrence was not limited to mares which fail to foal; in 2009, six mares had both a foal at foot and a sub-adult son or daughter present, and four of these sub-adults were male and continued to suckle. Additionally, adult body size does not determine dominance in feral horse mares (Berger, 1977); reproductive success of adult males is determined frequently by fighting ability, which depends more upon speed and agility than body mass (Berger, 1986). We, therefore, consider suckling in nutritionally independent offspring as indicative of increased comfort suckling by sub-adult males rather than prolonged provisioning by the mothers; this is supported by the higher levels of affiliative interactions between mothers and sons than with their daughters. Although these measures may not be independent of each other, they highlight the fact that both parties actively maintain the close relationship.

The benefits to mothers of allowing a closer relationship with sons may explained by the benefits of delayed dispersal. Decisions to delay dispersal in males often reflect their competitive ability (Clarke et al., 2008), the number of peers available in the natal band (Rutberg \& Keiper, 1993) or the likelihood of oestrus females being available elsewhere (Dunbar et al., 1990). Dispersal is inherently risky (Dunbar, 1987; Isbell \& vanVuren, 1996; Jack \& Isbell, 2009) due to the dangers of predation (Alberts \& Altmann, 1995), not finding a suitable bachelor group to join and potential injuries from aggression inflicted by members of the new group (Rutberg, 1990). Social skills gained by staying in the natal herd may help reduce this risky period between dispersal and harem formation (Khalil \& Murakami, 1999). Delayed dispersal by colts, therefore, has benefits in terms of increasing social skills, which are improved by experience and repeated interactions with other individuals, in an environment where social support is available from their mother. 
We show male horses' spatial centrality increases with age, reflecting more extensive interactions within the band. The wider circle of interactions may help explain why colts receive higher aggression levels than their female peers. As a response to this aggression, dams are able to offer continued social support and allow males to delay dispersal (Kaseda et al., 1984).

Female dispersal is not linked to aggression by mares or stallions in the natal group (Monard et al., 1996). They instead disperse upon first reaching oestrus (Rutberg \& Keiper, 1993), particularly if they suffer from increased attention from the resident stallion (their most likely sire). Increasing social integration was less apparent in sub-adult females as centrality did not increase with age. In primates, low social integration has been shown to correlate with increased likelihood of dispersal (Ekernas \& Cords, 2007); a weakening of the mother-offspring bond over time may contribute towards a female's decision to disperse.

The two centrality measures give consistent results for males (increasing centrality with age class) but the pattern for females differs slightly. The measures evaluate slightly different aspects of an individual's position. Closeness centrality is the reciprocal of the mean geodesic distance between the focal node and all other reachable nodes; as the geodesic distances increase, the centrality of the actor decreases (Wasserman \& Faust, 1994). High closeness centrality may, therefore, indicate either a large number of medium strength relationships or a small number of strong relationships. For adult males, the former would be true, whereas for females, a tight-knit clique (perhaps with others of high relatedness) is the likely reason for slightly (non-significantly) increasing closeness with age class. Betweenness centrality is the proportion of geodesics connecting all possible dyads within the band on which an actor lies (Wasserman \& Faust, 1994); therefore, for this to be high, an individual must be central to a larger number of relationships. It cannot be influenced by being a member of a small but close clique. The increasing centrality for males suggests they widen their circle of interactions as they mature. Females, conversely, increase their social interactions as sub-adults (reflecting social independence from the mother) then subsequently maintain strong bonds with only a small number of individuals (Feh, 2005). Thus, these two measures provide insight into different aspects of an individual's social position within the group.

The effect of season on mare behaviour (but not on stallion aggression towards youngsters) is an interesting additional result. Affiliative behaviour 
towards offspring is greatly increased during June, July and August since most of the foals are born between April and May; mothers and foals are, therefore, in close proximity in the summer months as the young foal is still suckling, with affiliative behaviour helping to cement the mother-offspring bond. The concurrent increase in aggression towards non-offspring youngsters may also be partly explained by their protection of dependent foals, as well as by avoidance of suckling attempts by foreign foals. However, since sub-adult colts have been recorded sexually harassing mares during this study, this may further explain the increase in aggression. These early sexual attempts become more frequent as mares come into season following foaling (personal observation); since such harassment can cause loss of condition (Linklater et al., 1999), mares' attempts to evict young males become more frequent.

To conclude, we have shown that sex differential investment in nutritionally independent offspring may occur in horses. We explain this in terms of the sex differential benefits of delaying dispersal. We propose that in horses, females leave their band voluntarily upon first oestrus, whilst for colts, the timing of dispersal is the outcome of conflict between the mother-offspring dyad (who attempt to delay dispersal to an optimal time) and other herd members, principally the stallion (who attempt to evict them at an earlier stage). The benefits to colts of delaying dispersal are increased opportunities for social learning and integration, a necessary progression towards becoming a successful breeding stallion. The use of social network metrics allowed an explicit examination of social position within the band and highlighted the difference between maturing males and females. It is possible that similar social learning occurs in a range of ungulates; this might be expected in any species where a significant time gap occurs between nutritional independence and dispersal.

\section{Acknowledgements}

This work was supported by a Royal Society Dorothy Hodgkin Fellowship awarded to SS. We would also like to thank the Carneddau pony society, Snowdonia National Park and the National Trust for permitting us to work with the population and to Claudia Mettke-Hofmann, Filippo Aureli and three anonymous referees for their comments on this manuscript. 


\section{References}

Alberts, S.C. \& Altmann, J. (1995). Balancing costs and opportunities — dispersal in male baboons. - Am. Nat. 145: 279-306.

Altmann, J. (1974). Observational study of behaviour: sampling methods. — Behaviour 49: 227-265.

Aureli, F., Schafner, C.M., Boesch, C., Bearder, S.K., Call, J., Chapman, C.A., Conner, R., Difiore, A., Dunbar, R.I.M., Henzi, S.P., Holekamp, K.E., Korstjens, A.H., Layton, R.H., Lee, P., Leymann, J., Manson, J.H., Ramos-Fernandez, G., Strier, K.B. \& van Schaik, C.P. (2008). Fission-fusion dynamics: new research frameworks. — Curr. Anthropol. 49: 627-654.

Barber, J.A. \& Crowell-Davis, S.L. (1994). Maternal behaviour of Belgian (Equus caballus) mares. - Appl. Anim. Behav. Sci. 41: 161-189.

Berger, J. (1977). Organisational systems and dominance in feral horses in the Grand Canyon. — Behav. Ecol. Sociobiol. 2: 131-146.

Berger, J. (1986). Wild horses of the Great Basin. - University of Chicago Press, Chicago, IL.

Cairns, S.J. \& Schwager, S.J. (1987). A comparison of association indices. — Anim. Behav. 35: $1454-1469$.

Cameron, E.Z. \& Linklater, W.L. (2000). Individual mares bias investment in sons and daughters in relation to their condition. - Anim. Behav. 60: 359-367.

Cameron, E.Z., Linklater, W.L., Stafford, K.J. \& Minot, E.O. (2000). Aging and improving reporoductive success in horses: declining residual reproductive value or just older and wiser? - Behav. Ecol. Sociobiol. 47: 243-249.

Cameron, E.Z., Linklater, W.L., Stafford, K.J. \& Veltman, C.J. (1999b). Birth sex ratios relate to mare condition at conception in Kaimanawa horses. - Behav. Ecol. 10: 472-475.

Cameron, E.Z., Stafford, K.J., Linklater, W.L. \& Veltman, C.J. (1999a). Suckling behaviour does not measure milk intake in horses, Equus caballus. - Anim. Behav. 57: 673-678.

Clarke, P.M.R., Henzi, S.P., Barrett, L. \& Rendall, D. (2008). On the road again: competitive effects and condition-dependent dispersal in male baboons. - Anim. Behav. 76: 55-63.

Clutton-Brock, T.H., Albon, S.D. \& Guinness, F.E. (1984). Maternal dominance, breeding success and birth sex ratios in red deer. - Nature 308: 358-360.

Clutton-Brock, T.H., Guinness, F.E. \& Albon, S.D. (1982). Red deer: behaviour and ecology of two sexes. - University of Chicago Press, Chicago, IL.

Croft, D.P., James, R. \& Krause, J. (2008). Exploring animal social networks. — Princeton University Press, Princeton, NJ.

Crowell-Davis, S.L. (1985). Nursing behaviour and maternal aggression among Welsh ponies (Equus caballus). - Appl. Anim. Behav. Sci. 14: 11-25.

Csardi, G. (2011). igraph package version 0.5.5-1. - Available online at http://igraph. sourceforge.net (accessed on 1 August 2011).

Dunbar, R.I.M. (1987). Habitat quality, population-dynamics, and group composition in colobus monkeys (Colobus guereza). — Int. J. Primatol. 8: 299-329.

Dunbar, R.I.M. (1998). The social brain hypothesis. — Evol. Anthropol. 6: 178-190. 
Dunbar, R.I.M., Buckland, D. \& Miller, D. (1990). Mating strategies of feral goats: a problem in optimal foraging. - Anim. Behav. 40: 653-667.

Duncan, P., Harvey, P.H. \& Wells, S.M. (1984). On lactation and associated behaviour in a natural herd of horses. - Anim. Behav. 32: 255-263.

Ekernas, L.S. \& Cords, M. (2007). Social and environmental factors influencing natal dispersal in blue monkeys, Cercopithecus mitis stuhlmanni. — Anim. Behav. 73: 1009-1020.

Fairbanks, L.A. (1996). Individual differences in maternal style: causes and consequences for mothers and offspring. - Adv. Stud. Behav. 25: 579-611.

Feh, C. (1999). Alliances and reproductive success in Camargue stallions. - Anim. Behav. 57: 705-713.

Feh, C. (2005). Relationships and communication in socially natural horse herds. - In: The domestic horse - the evolution, development and management of its behaviour (Mills, D. \& McDonnell, S., eds). Cambridge University Press, Cambridge.

Hall, R. \& Kirkpatrick, J.E. (1975). Biology of the Pryor mountain wild horse. — US Department of the Interior, Bureau of Land Management, Salt Lake City, UT (unpublished paper).

Hansen, H., McDonald, D.B., Groves, P., Maier, J.A.K. \& Ben-David, M. (2009). Social networks and the formation and maintenance of river otter groups. — Ethology 115: 384396.

Houpt, K.A., Law, K. \& Martinisi, V. (1978). Dominance hierarchies in domestic horses. Appl. Anim. Ethol. 4: 273-283.

Isbell, L.A. \& van Vuren, D. (1996). Differential costs of locational and social dispersal and their consequences for female group-living primates. - Behaviour 133: 1-36.

Jack, K.M. \& Isbell, L.A. (2009). Dispersal in primates: advancing an individualized approach. - Behaviour 146: 429-436.

Joffe, T.H. (1997). Social pressures have selected for an extended juvenile period in primates. — J. Human Evol. 32: 593-605.

Johnson, J.B. \& Omland, K.S. (2004). Model selection in ecology and evolution. — Trends Ecol. Evol. 19: 101-108.

Kaseda, Y., Nozawa, K. \& Mogi, K. (1984). Separation and independence of offsprings from the harem groups in Misaki horses. — Japan. J. Zootech. Sci. 55: 852-857.

Khalil, A.M. \& Murakami, N. (1999). Effect of natal dispersal on the reproductive strategies of the young Misaki feral stallions. - Appl. Anim. Behav. Sci. 62: 281-291.

Kruuk, L.E.B., Clutton-Brock, T.H., Rose, K.E. \& Guinness, F.E. (1999). Early determinants of lifetime reproductive success differ between the sexes in red deer. - Proc. Roy. Soc. Lond. B: Biol. 266: 1655-1661.

Landherr, A., Friedl, B. \& Heidemann, J. (2010). A critical review of centrality measures in social networks. - Bus. Info. Syst. Eng. 2: 371-385.

Linklater, W.L., Cameron, E.Z., Minot, E.O. \& Stafford, K.J. (1999). Stallion harassment and the mating system of horses. - Anim. Behav. 58: 295-306.

Maestripieri, D. (1998). Social and demographic influences on mothering style in pigtail macaques. - Ethology 104: 379-385. 
Mills, D. \& McDonnell, S. (2005). The domestic horse - the evolution, development and management of its behaviour. - Cambridge University Press, Cambridge.

Monard, A.M., Duncan, P. \& Boy, V. (1996). The proximate mechanisms of natal dispersal in female horses. - Behaviour 133: 1095-1124.

Opsahl, T. (2011). tnet package version 3.0.3. - Available online at http://toreopsahl.com/ tnet (accessed on 1 August 2011).

Pan, W. (2001). Akaike's information criterion in generalized estimating equations. - Biometrics 57: 120-125.

Rutberg, A.T. (1990). Inter-group transfer in Assateague pony mares. - Anim. Behav. 40: 945-952.

Rutberg, A.T. \& Greenberg, S.A. (1990). Dominance, aggression frequencies and modes of aggressive competition in feral pony mares. — Anim. Behav. 40: 322-331.

Rutberg, A.T. \& Keiper, R.R. (1993). Proximate causes of natal dispersal in feral ponies: some sex differences. - Anim. Behav. 46: 969-975.

Sih, A., Hanser, S.F. \& McHugh, K.A. (2009). Social network theory: new insights and issues for behavioural ecologists. — Behav. Ecol. Sociobiol. 63: 975-988.

Trivers, R.L. \& Willard, D.E. (1973). Natural selection of parental ability to vary the sex ratio of offspring. - Science 179: 90-92.

Vervaecke, H., Stevens, J.M.G., Vandemoortele, H., Sigurjonsdottir, H. \& de Vries, H. (2006). Aggression and dominance in matched groups of subadult Icelandic horses (Equus caballus). - J. Ethol. 25: 239-248.

Wasserman, S. \& Faust, K. (1994). Social network analysis: methods and applications. Cambridge University Press, Cambridge.

Weeks, J.W. (2000). Maternal investment in Equus caballus. — PhD thesis, The University of Georgia, Atlanta, GA. 